\title{
Explore the Integration of Cost Leadership Strategy and Differentiation Strategy
}

\author{
An Geng ${ }^{1}$,and Lifen Chen $^{2}$ \\ ${ }^{1.2}$.School of Economics and Management, Nanjing University of Science and Technology, Nanjing \\ 210094,China \\ 1151249921@qq.com;njustclf@163.com
}

\section{Keywords: Differentiation Strategy; Low Cost Strategy; Integration}

\begin{abstract}
Cost-leading strategies and differentiation strategies have their own characteristics and scope of application. However, with the change of modern production management mode and the development of information network technology in the information economy era, a single competitive strategy can not get competitive advantage. In real life, in most industries, if an enterprise can do both the effective difference, but also to maintain a low price, then it is possible to become the market leader. This paper focuses on the strategy of cost leadership strategy and differentiation strategy, and discusses the advantages and disadvantages of the two strategies. Finally, it discusses the ways of integrating the two strategies, hoping to provide some enlightenment for the two strategic management of the enterprise.
\end{abstract}

\section{The Literature Review}

Porter, a professor at Harvard Business School in the United States, puts forward three general competitive strategies in his classic "Competitive Strategy", namely, cost leadership strategy, differentiation strategy, and centralization strategy. He believes that low cost and differentiation are incompatible. While the pursuit of low-cost advantages and differences advantages of enterprises easily caught in the "caught in the middle" of the predicament, and only get less than the average level of profits.A number of scholars' studies have also supported Porter's point of view, for example. Thornhils et al. (2007) found that a single strategy is often better than a composite strategy in some industries[1]. There are also some scholars who study the cost of leading strategies and differentiated strategies which are better. Zhang's empirical study shows that, compared with the low-cost strategy, the differentiation strategy has a more significant positive impact on the product innovation[2]. The research by Bao (2014) shows that $\mathrm{R} \& \mathrm{D}$ investment under the differentiation strategy can improve the performance of enterprises, and the $\mathrm{R} \& \mathrm{D}$ investment under the cost leadership strategy is impaired[3].

With the external environment continues to change, more and more scholars began to focus on strategic integration. The study of Philips et al (1983) found that the differentiation characteristics of a product are positively correlated with market share, that is, the greater the degree of product differentiation, the higher the market share. And the market share and the direct cost of negative correlation, that is, the lower the cost of its product market share, but lower, so differentiation is the way to achieve cost leadership[4]. This also proves that differentiation and low cost are not antagonistic strategies. Beal and Yasai-Ardekani (2000) from the theoretical level demonstrated the possibility of the integration of the two strategies. Domestic scholars have also begun to study the two strategic integration[5]. Rui and Li (2007) argue that differentiation strategies and cost-leading strategies are not mutually exclusive, and in some cases, there is internal consistency. Through the cost-leading strategy to form a competitive advantage, in essence, is a differentiated strategy[6]. Zhou (2012) that the development of information technology, consumer centrality and the integration of the value chain for the two strategic integration provides a node[7]. Wengi (2009) proposed an all-environment interaction model, and test the advantages of strategic integration[8]. $\mathrm{Xu}$ et al. (2013) constructed a framework for integrating cost leadership and differentiation strategies from the perspective of business outsourcing and e-marketing[9]. 
To sum up, the current research on the cost leadership strategy and differentiation strategy can be implemented in parallel there is no uniform conclusion. Even in the study that the cost strategy and the differentiation strategy can be fused, the two strategic integration perspectives are also different. This paper first describes the importance of strategic integration, and then analyze the two strategies in parallel implementation environment, and further elaborate two strategies in parallel specific ways.

\section{The Meaning of Integration}

Companies that adopt differentiation strategies typically offer personalized products and services to customers, so the prices are generally higher; companies that implement cost-leading strategies have a price advantage but are unable to meet the increasing demands of consumers. Differentiated strategies are likely to get higher profits than low-cost strategies, and cost-leading strategies are more likely to increase market share. Regardless of cost leadership strategy or differentiation strategy has its shortcomings, if the enterprise alone to adopt a strategy can not get a clear competitive advantage in the modern competitive environment. And the effective integration of the two strategies can bring great advantages for the enterprise. According to Porter's five-force competition as the model, the author elaborates the significance of the integration strategy.

For Suppliers. The enterprise has both large orders that are difficult to resist by suppliers and higher margins. Simply implement the total cost of leading companies trying to squeeze the profit margins of suppliers to achieve their own low-cost, and the use of portfolio strategy enterprises can be more flexible choice of bargaining chips, such as the appropriate increase in the purchase price at the same time require other services.

For Buyers. Inexpensive will continue to attract consumers. While consumers have differentiated brand loyalty, companies can maximize consumer surplus through lower prices, resulting in higher reputation and loyalty. In addition, the lower prices will also expand the group of buyers, effectively reducing the risk of interest in the transfer of interest in the target market.

For the Current Competitors. At the same time have a cost advantage and differentiation advantages of the enterprise will compete with the opponent to occupy a favorable position. Its mutually supportive cost strategy and differentiation strategy enable companies to have a strong competitive weapon. Enterprise products are of good quality compared to other products at the same price, with lower prices than other products of the same quality. Enterprises do not have to take the initiative to launch a price war will be able to occupy the high share of the market, while no fear of price war.

For Alternatives. As a result of the characteristics, but also won the trust of customers, while competing with alternative products have a price advantage, companies will be able to greatly extend the life cycle of existing products, is conducive to enterprises to recover pre-costs, and provide sufficient time and financial support for the upgrading of enterprise products.

For Potential Entrants. Cost advantages and customer loyalty to the enterprise (or product) form a strong double entry barriers, and potential entrants to enter the industry will face greater difficulties. Through the above discussion, we can see the success of the cost leadership and differentiation of the strategic combination will bring lasting and unique core competitiveness of enterprises.

\section{The Feasibility Analysis of the Strategic Integration}

The application of information technology can simultaneously achieve cost leadership and differentiation strategies. The application of information technology can strengthen the characteristics of products or services, and more and more enterprises began to continue to use information technology to provide differentiated services to meet the needs of different users personalized. while a variety of modern information systems reduce the operating costs. In particular, information technology to improve the internal and external synergies between enterprises, reducing the internal and external transaction costs. Enterprises through the use of 
appropriate information technology to optimize the allocation of resources and capabilities, to achieve cost leadership and differentiation of both.

Modern forms of organization can simultaneously achieve cost leadership and differentiation strategies. The successful implementation of each competitive strategy should be organized to adapt and support. The cost leadership strategy requires that the organizational structure be characterized by specialization, centralization and standardization, The differentiation strategy requires the decentralization of functions and the flattening of organizational structure and the flexibility of the system. These two different organizations require that they can not be achieved at the same time in traditional organizational design. However, with the expansion of management and the wide application of information technology, organizations that can meet these two characteristics at the same time come into being, for example, Learning organization, borderless organization and team organization. These new organizational structure meet the requirements of the integration of competitive strategy implementation. In addition, business department system has also contributed to the organization to achieve cost leadership and differentiation at the same time. Since the competitive strategies of the different divisions are independent, the cost leadership strategy can be implemented in one division, and the differentiation strategy is implemented in the other business units.

Diversification of customer needs. Integration of the competitive strategy of the face of the customer is not only price-sensitive customers and value-sensitive customers two types. On the contrary, with the development of commodity economy and the improvement of living standards, more and more customers not only want to get low prices of products, and hope that products meet their diverse and personalized needs. Even in the same level of customer groups, enterprises are facing a variety of market segments, and only two levels of high and low to divide the target market is difficult to achieve the purpose of corporate information transmission. In other words, the needs of customers in real life are extremely diverse, and the degree of differentiation and price can be combined in a variety of combinations. "This is the traditional competitive strategy Porter theory ignores the market gap, but also the integration of competitive strategy established customer base".

Mass customization technology and management models can integrate cost leadership strategy and differentiation strategy of product characteristics and technology requirements. Cost leadership strategy of standardized products need to reduce costs through large-scale production, differentiation strategy of non-standardized products is to meet the individual needs of customers. In the industrialized period, it is almost impossible to combine the advantages of these two strategies, but the development of information network technology has led to the emergence of mass customization. Mass customization is usually combined with the "direct sales" model, which reduces the cost of the channel network and inventory of the enterprise, and can provide differentiated services, finally realize the integration of the cost advantage and the differentiation advantage. However, it is important to note that mass customization is required to cooperate with enterprise information technology and agile manufacturing systems. If the enterprise does not have a sound information technology platform and a highly effective flexible manufacturing process, mass customization is difficult to implement.

\section{The Practice of Strategic Integration}

Mass Customization. Mass customization is a common way to achieve cost leadership and differentiation requirements. On the one hand, enterprises achieve economies of scale and reduce costs through modular production and reduce costs. On the other hand, according to the individual needs of different customers, the enterprise achieves the different needs of customers through different combinations of different modules.

Scissors Poor Management Model. Enterprises can be divided into two management systems, that is, a manufacturing system, the other for the R \& D and sales system. In the first system, enterprises take cost leadership strategy to strictly control the cost, in the second system, the enterprise uses the differentiation strategy to meet the individual needs of consumers. Of course, there is integration and link between the strategies of the two systems. In addition, the incentive 
mechanism for the two systems is also different. For example, in a manufacturing system, the company should reward employees who provide innovative methods to reduce costs, and develop a more personalized product as as a reward standard in the R \& D system. Therefore, the scissors difference management model effectively avoid the contradiction between the two strategies to promote the integration of low cost and differentiation.

Information Network Technology. With the development of information network technology, more and more enterprises began to use information technology to provide differentiated services to meet the individual needs of different users, while enterprises can rely on a variety of modern information systems to reduce operating costs, so that enterprises both provide differentiated services, but also make the cost ahead of the competitors, to achieve the balance of cost leadership and differentiation. Enterprises that implement the converged competitive strategy should make full use of modern information technology, fundamentally transform and reorganize business processes, and rebuild flexible manufacturing systems that can support fast response, small batch and variety, and realize the effective integration of low cost advantage, speed advantage and differentiated product advantages.

Strategic Alliances. Different enterprises in the same industry may be based on their own resources, ability, organizational structure, and culture to develop a different competitive strategy. If building strategic alliances among different enterprises with different competitive strategies in the same industry, by using the organizational flexibility, the ambiguity of the boundary, the loosening of the relationship, the operation efficiency and the the advantages combination of the strategic alliance, the enterprise can make use of the simple alliance to make up the shortage of the resource ability, and effectively use the strategic alliance to achieve the complementary advantages and resource sharing between enterprises[10]. These ultimately contribute to the cost advantage and the difference between the advantages of integration.

Total Quality Management. Total quality management has formed a complete set of methodologies that are popularized in many enterprises. Existing studies have shown that total quality management has a positive impact on the competitive advantage[11] Effective implementation of total quality management can bring the following advantages to the enterprise: improve product quality and meet customer demand for availability and reliability of product; increase product and price attractiveness to reduce customer turnover rate; by reducing the defective occurrence rate and rework rate to reduce the need for maintenance services and the product costs. It can be seen that total quality management is an effective means of taking into account cost leadership and differentiation.

\section{Conclusion}

Based on the idea that differentiation strategy and cost leadership strategy can be integrated, this paper elaborates the necessity of strategic integration and the feasibility of integration theory, and further explores the current practice of strategic integration. However, this paper only elaborates from the theoretical point of view, and the future research direction should be from the simple integration of strategic feasibility research to the establishment of strategic integration model and specific guidance on how to implement the integration of these two strategies.

\section{Reference}

[1] Thornhill, S. and R.E. White, Strategic purity: A multi-industry evaluation of pure vs. hybrid business strategies, [J]. Strategic Direction. Vol. 28(2007) No.9, p.553-561.

[2] J. Zhang, C. Qi, The Impact of Competitive Strategy on Product Innovation of Exporters: Via Market Orientation as Mediating Variable,[J]. Management Review. Vol. 23(2011) No.7, p.53-61.(in Chinese)

[3] X.J. Bao, Y. Sun, Q.Y. Tao, Study on the Relationship among Competitive Strategy, Innovation R\&D Investment and Enterprise Performance, [J]. Forum on Science and Technology in China. (2014) No.6, p.63-69.(in Chinese) 
[4] Phillips L W, Chang D R, Buzzell R D, Product Quality, Cost Position and Business Performance: A Test of Some Key Hypotheses, [J]. Journal of Marketing. Vol.47(1983) No.2, p.26-43.

[5] Beal R M, Yasai-Ardekani M, Performance Implications of Aligning CEO Functional Experiences with Competitive Strategies, [J]. Journal of Management: Official Journal of the Southern Management Association. Vol. 26(2000) No.4, p.733-762.

[6] Y.L. Liu, Analysis of the Cost Leading Strategy of Differentiation, [J]. Money China. (2010) No.10, p.95-95.(in Chinese)

[7] S. Zhou, An Analysis of the Integration of Enterprise Cost Leadership Strategy and Differentiation Strategy, [J]. China Management Informationization. Vol.15(2012) No.4,p.29-31.(in Chinese)

[8] J.Y. Weng, Refining Generic Strategy for Doing Business in Fast Changing Environments, [J]. China Industrial Economics. (2009) No.3, p.92-101.(in Chinese)

[9] W.L. Xu, M.J. Wu, J.Y. Huang, The Study on Parallel Implementation of Cost Leadership and Differentiation Strategies, [J]. Soft Science. Vol. 27(2013) No.10,p.45-49.(in Chinese)

[10] S.P. Cheng, Q.Y. Peng, Analysis on the Mechanism of Competitive Advantage of Enterprise Strategic Alliance, [J]. Journal of Commercial Economics. (2007),p.28-30.(in Chinese)

[11] G.M. Zhang, F. Xu, Relationship between Total Quality Management, Business Innovation Capability and Competitive AdvantageBased on Resource Based View and Dynamic Capability View, [J]. Science and Technology Management Research. (2017),p.39-45.(in Chinese) 